\title{
ASSESSMENT OF ECONOMIC FEASIBILITY FOR GRID- CONNECTED RENEWABLE ENERGY SYSTEM FOR A HOUSEHOLD APPLICATION IN TERENGGANU
}

\author{
W.M.W. MUDA ${ }^{1,2} \&$ ROSLAN UMAR ${ }^{3}$ \\ ${ }^{1}$ Special Interest Group of Eastern Corridor Renewable Energy, University Malaysia Terengganu, Malaysia. \\ ${ }^{2}$ School of Ocean Engineering, University Malaysia Terengganu, Malaysia. \\ ${ }^{3}$ East Coast Environment Research Institute, University Sultan Zainal Abidin, Malaysia.
}

\begin{abstract}
This article extends the conference paper 'Simulation-based method to evaluate PV/wind hybrid renewable energy system in Terengganu'. Instead of off-grid system considered in the conference version, inspired by feed-in-tariff introduced by The Government of Malaysia, this article includes grid-connected hybrid renewable energy system to examine their feasibility to be used as power supply for a household in Terengganu. In addition, this article compares the performance of grid-only system and hybrid grid-renewable energy systems in terms of cost of electricity and emission of pollutant. The payback period is also examined based on the current sellback rate. Sensitivity analysis is done to find the best sellback rate for a hybrid grid/PV/wind system to compete with a hybrid grid/PV system. In addition, the most optimal configuration is also determined by varying the value of solar radiation, wind speed and sellback rate. Generally, it is concluded that the hybrid grid/PV system is the most practicable choice to be used as power generator to supply electricity for a household in Terengganu.

Keywords: cost of energy, economic analysis, feed-in-tariff, grid-connected system, HOMER software, optimal configuration, payback period, renewable energy, sensitivity analysis.
\end{abstract}

\section{INTRODUCTION}

Ardakani and Ardehali [1] predicted that the energy consumption increases in the whole world due to increasing number of populations, vehicles, buildings, factories and electronic devices. With the increase of energy demand, Energy Information Administration (EIA) [2] predicted that the cost of electricity rises too. Increase in the cost of electricity affects the cost of living for a household especially the poor. To reduce dependency on fuel, using renewable energy sources as power generator is the best option as they are clean and emission-free. According to the study conducted in ten countries in Asia Pacific by Benjamin [3], six of them have successfully implemented renewable energy to be used as electricity generator for rural communities. However, Malaysia is one of the four countries considered that fail or does not achieve the target to do so. There are ten factors listed by Benjamin [3] that contribute to the success in executing the renewable energy for small systems. Some of the reasons why Malaysia cannot implement Small Renewable Energy Power (SREP) program were because of lack of marketing by government, local bank were reluctant to cover the renewable energy sector; because of lack of awareness and unfamiliar with green technologies, the communities also felt isolated with this technology.

To solve the SREP difficulty, Malaysia has introduced Feed-in-Tariff (FiT) in Tenth Malaysia Plan [4] to promote the use of renewable energy among consumers. This technique is applied by other developing countries as mentioned by Abdullah et al. [5]. Meanwhile, Sustainable Energy Development Authority (SEDA) [6] of Malaysia is a statutory body to administer and manage the implementation of the FiT mechanism, which is mandated under the Renewable Energy Act 2011 (no. 725). 
In Malaysia, there are various types of renewable energy sources that have been identified by Rosnazri et al. [7]. As an equatorial country, Malaysia has approximately $4000-5000 \mathrm{Wh} / \mathrm{m}^{2}$ of daily average solar radiation and thus the potential for solar power generation is very high. It has been estimated that the energy obtained from solar is at four times the world fossil fuel resources. However, producing energy from wind in Malaysia is still limited due to low average wind velocity in the whole country. The wind speed in Malaysia is low and varies from season to season in the range of $2-13 \mathrm{~m} / \mathrm{s}$. However, there are potential places that have been identified by Rosnazri et al. [7] to generate electricity from wind energy such as Terengganu, Sabah and Johor.

Both solar and wind energy are strongly depended on weather conditions, which are solar radiation and wind speed, respectively. Basically, when the solar radiation is high, the wind speed is low and vice versa. As a result, combination of these two sources to perform a photovoltaic/wind (PV/W) hybrid system is a good option. This system is suitable to be used in rural areas and islands to replace the use of generator as studied by Rozlan et al. [8]. Thus, recently the economical analysis of PV/W hybrid system has been investigated by Muda and Fong [9] using HOMER software [10] to get general idea of the optimum configuration in supplying electricity for a household particularly in Terengganu. However, the system considered by Muda and Fong [9] is off-grid and suitable for remote area only. Furthermore, most of the configurations discussed by Muda and Fong [9] produce high percentage of excess electricity. This excess electricity can be sold to grid to generate income and reduce electricity bills. Thus, inspired by FiT scheme, this article extends the conference paper of Muda and Fong [9] by exploring grid-connected renewable energy system for a household application in Terengganu.

In this study, the feasibility of three configurations which are hybrid PV/grid, hybrid PV/ wind/grid and hybrid wind/grid are simulated. The performance of these configurations is compared with the current system, which is grid-only system, based on the cost of electricity, electricity production and consumption, and the emission of pollutant. The payback period of the three configurations is also determined based on the grid-only system. In addition, the sensitivity analysis is done to determine the payback period for different FiT rates and different load profiles. The values of wind speed and solar radiation are also varied to find the most optimal system in different locations.

\section{ASSESSMENT CRITERIA}

There are a few parameters that can be considered in analyzing the economic viability of energy production from the proposed system as discussed by Gilbert [11]. In this article, consumers are interested in the cost of energy (COE) and simple payback period.

\subsection{Cost of energy}

COE also known as cost of electricity is the cost that has to be paid by the consumer for $1 \mathrm{kWh}$ of energy consumed $(\$ / \mathrm{kWh})$. In Malaysia, the price rate is determined by Tenaga Nasional Berhad (TNB) [12]. The latest price rate was increased in 2014 and it is predicted to be increased in the future. By knowing the $\mathrm{COE}$, consumer can compare with the price rates given by TNB and the lowest COE is the best choice. The list of COE in Malaysia can be referred in [12].

\subsection{Simple payback period}

Sincle the capital cost and the replacement cost of renewable energy are high, consumers need to know how long it would take to recover the amount of money that have been invested 
in renewable energy technology. HOMER [10] calculates the simple payback period by comparing the proposed system with the base case, which is in this case, the grid-only system. The best configuration should offer the shortest simple payback period.

\section{DATA COLLECTION}

Similar to [9], the selected area of this study is in Terengganu with the latitude and longitude being 5.31 and 103.12, respectively. HOMER software requires some input parameters to calculate the optimization results for a specific configuration of system. The input parameters are daily solar radiation $\left(\mathrm{kWh} / \mathrm{m}^{2} / \mathrm{d}\right)$, wind speed $(\mathrm{m} / \mathrm{s})$, load profile $(\mathrm{kW})$ and grid specification.

\subsection{Solar radiation, wind speed and load profile}

Similar to [9], the solar radiation and wind speed data were obtained from National Aeronautics and Space Administrative (NASA) [13]. The plot of solar radiation and wind speed for the selected area can be referred in Figs 3 and 4 of [9]. Load profile shows the trend of electricity consumption in daily life of the selected consumer. A similar load profile as in [9] was used in this study as illustrated in Fig. 5 of [9].

\subsection{Grid specification}

In Malaysia, the generation and distribution of electricity is conducted by TNB [12]. Tariff rates that use monthly basis for domestic consumer can be obtained in [12]. Different rates are given based on the amount of electricity used. For a household application with the load profile as considered in this article, the amount of electricity used is approximately $255 \mathrm{kWh} /$ month. Since HOMER only allows different rates using time basis, the average price rate for electricity purchased from the grid for the selected load profile is RM $0.245 / \mathrm{kWh}$. Since all the components price are in USD, the price rate is set at $\$ 0.0772$ using the same exchange rate as in [9] at USD $1=$ MYR 3.1746.

Feed-in-tariff (FiT) is controlled by SEDA [6]. Since the FiT was implemented in January 2012, the rate was decreased a few times. The sellback rate used in this article based on the current price is implemented since January 2015. By referring to SEDA [6], the FiT rate for an individual with the capacity of PV less than $4 \mathrm{~kW}$ is RM $0.9166 / \mathrm{kWh}$. Additional bonus RM $0.1722 / \mathrm{kWh}$ is given for rooftop installation, so the total sellback rate is set at RM $1.0888 / \mathrm{kWh}=\$ 0.3429 / \mathrm{kWh}$. However, the FiT for wind system has not been implemented. Therefore, in this study, first, the sellback rate for all configurations are set to be the same rate as PV system. Then, for economic analysis, FiT rate for configuration with wind turbine was varied from $\$ 0.3429 / \mathrm{kWh}$ to $\$ 0.5481 / \mathrm{kWh}$.

\section{SYSTEM DESCRIPTIONS AND SPECIFICATION}

The design specification, initial and replacement costs, and operating and maintenance cost for each component used in the system were provided in [9]. Since the proposed system in this article is grid-connected, grid is added in the system. Grid can also be used for storage when there is excess electricity. Therefore, battery is removed from the configuration. The system configuration of the proposed system is shown in Fig. 1. 


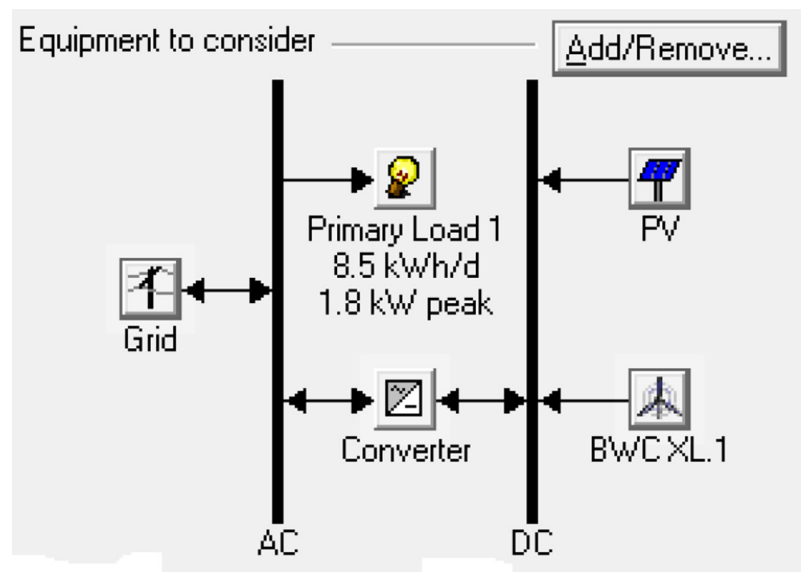

Figure 1: System configuration.

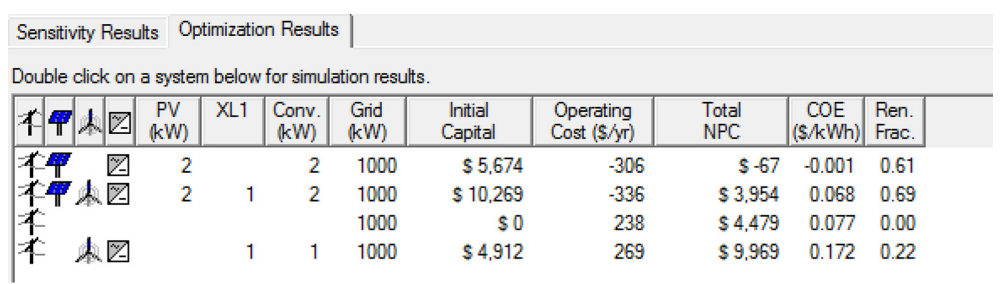

Figure 2: The optimization results.

\section{RESULTS AND DISCUSSION}

The optimization results rank the most optimal system based on the COE value. The performance of all configurations is compared based on COE, electricity production and consumption, and emission of pollutant. Then, the payback period is determined for all configurations. Lastly, the sensitivity analysis is done to find the best FiT rates for wind turbine to compete with PV system.

\subsection{Comparison between different configurations}

Figure 2 shows the optimization results obtained using the specification given in the previous section. There are four different configurations that are feasible to be used to supply electricity to the load demand. From the figure, the most optimal configuration is PV/grid hybrid system that consists of $2 \mathrm{~kW}$ PV panels, the maximum purchase capacity from the grid is $1000 \mathrm{~kW}$, and $2 \mathrm{~kW}$ converters. The electricity production and consumption for all four configurations are plotted in Figs 3 and 4, respectively.

\subsubsection{Grid-only system}

Grid-only system is widely used to supply electricity for a household in Malaysia. However, in this study, Fig. 2 shows that this system is not the most optimal system. Although the initial cost is $\$ 0$ because it is provided by TNB [12], the COE is higher than PV/grid system and PV/wind/ 
grid system. The COE stated in Fig. 2 is equal to tariff rates given by TNB. The total electricity produced by the grid is $3088 \mathrm{kWh} / \mathrm{yr}$ and is $100 \%$ used by the load.

\subsubsection{PV/grid system}

As in Fig. 2, grid-connected PV system is the most optimal system to be used for a household in Terengganu with the COE $\$-0.001 / \mathrm{kWh}$. The negative value of COE shows that the income obtained from selling electricity to grid is more than the money spent to buy electricity from grid. From Figs 3 and 4, this system can produce up to $4868 \mathrm{kWh}$ electricity per year and $61 \%$ of it is produced by PV array. The balanced $39 \%$ of electricity is purchased from the grid to supply electricity during electricity shortage, especially at night.

From the total amount of electricity consumption, $68 \%$ is used by load and another $32 \%$ is sold to the grid. Although the capacity of electricity purchased from the grid is higher than the amount sold to the grid, the energy charge is negative because the sellback price is higher almost four times than the tariff rate. Although FiT is very beneficial for consumer, this information is not informed well among them. The negative value of net present cost (NPC) for grid contributes to negative NPC, COE and operating cost for the system, as shown in the cash flow of this system in Fig. 5.

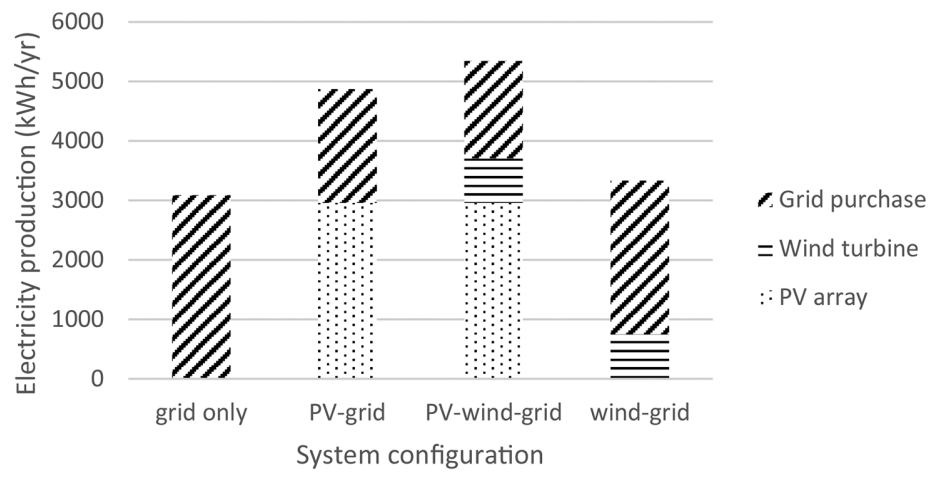

Figure 3: Electricity production for four configuration.

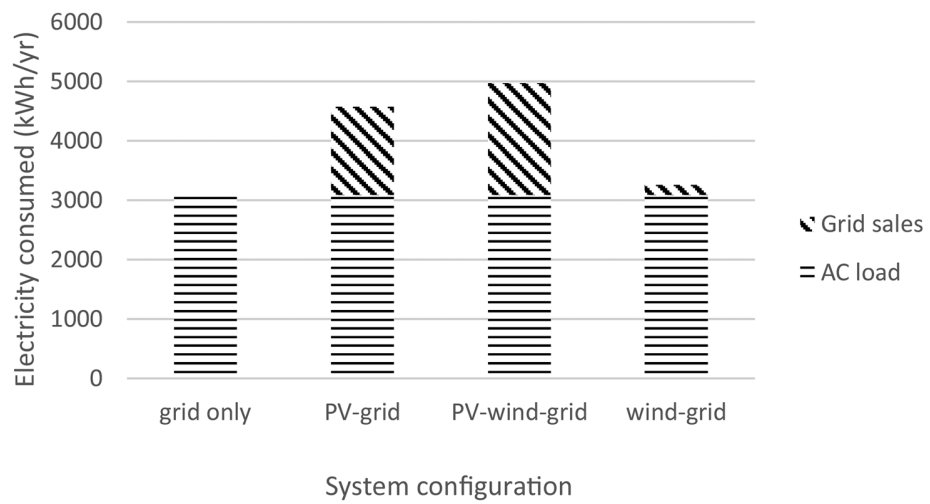

Figure 4: Electricity consumption for four configurations. 


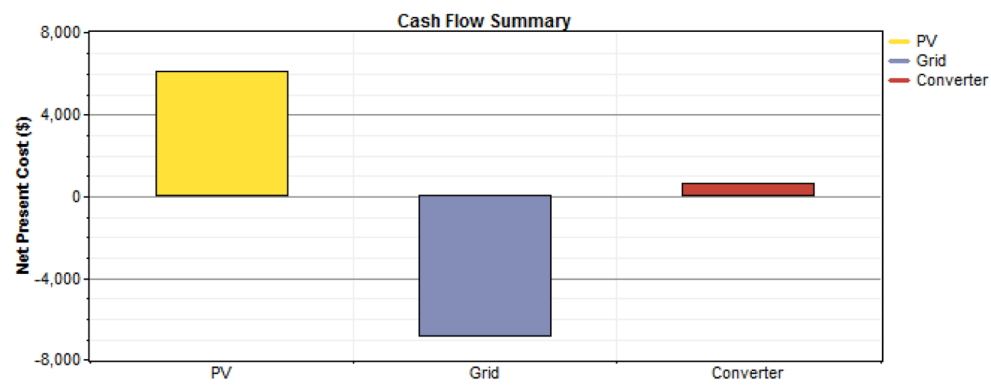

Figure 5: Cash flow summary for PV/grid system.

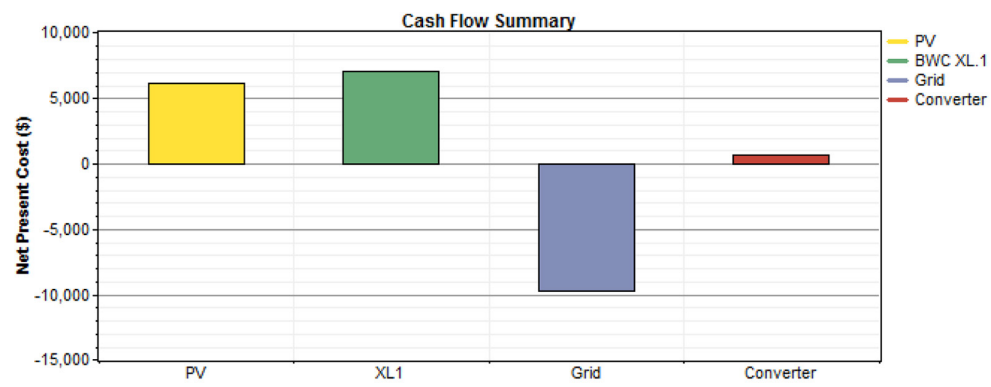

Figure 6: Cash flow summary for PV/wind/grid system.

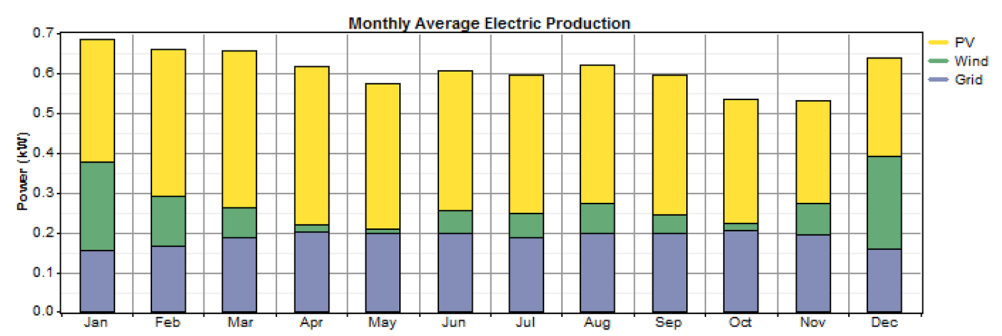

Figure 7: Monthly average electric production for PV/wind/grid system.

\subsubsection{PV/wind/grid system}

$\mathrm{PV} /$ wind/grid system is also more optimal compared to grid-only system. The COE for this system is cheaper than price rates determined by TNB. Although the NPC of grid for this system is more negative compared to PV/grid system, the positive value of total NPC and $\mathrm{COE}$ is contributed by the cost of wind turbine, which is very expensive as shown in Fig. 6. Since Terengganu receives high wind speed during the northeast monsoon, the electricity produced by wind turbine during that period is high as shown in Fig. 7. However, the total electricity produced by wind turbine is only $14 \%$ of total electricity production. Another $55 \%$ is produced by PV array and $31 \%$ is purchased from the grid with the total electric production of $5344 \mathrm{kWh} / \mathrm{yr}$. Since load uses only $3088 \mathrm{kWh} / \mathrm{yr}$, the amount of electricity can be sold to the grid for this system is higher than PV/grid system. 


\subsubsection{Wind/grid system}

From Fig. 2, wind/grid system is the worst choice in supplying electricity for a household in Terengganu. The COE for this system is higher than tariff price offered by TNB [12]. It happens because the electricity produced by wind is low, i.e. only $22 \%$ of the electricity production. The remaining $78 \%$ of electricity is needed to be bought from the grid as shown in Fig. 3. There is small percent of electricity that can be sold to the grid especially during the northeast monsoon when the wind speed is high; however, it is not enough to generate income. Since the amount of electricity purchased from the grid is higher than the amount of electricity sold to the grid, the NPC of the grid is positive as shown in Fig. 8. It contributes to high NPC and COE of the system.

\subsection{Emission of pollutant}

Since all configurations considered in this study are grid-connected, there must be emission generated by the grid as shown in Table 1. As expected, there were significant amounts of reduction in emission where the grid-connected system is a hybrid with renewable energy sources compared to grid-only system. Basically, the less energy purchased from the grid, the less emission the pollutant is. The reduction of emission for PV/grid system is reduced to $86 \%$ from the grid-only system. The negative value of emission of PV/wind/grid system occurring due to the amount of electricity purchased from the grid is less than the amount of electricity sold to the grid. HOMER simply calculates the emission by multiplying the net electricity purchases with emission factor.

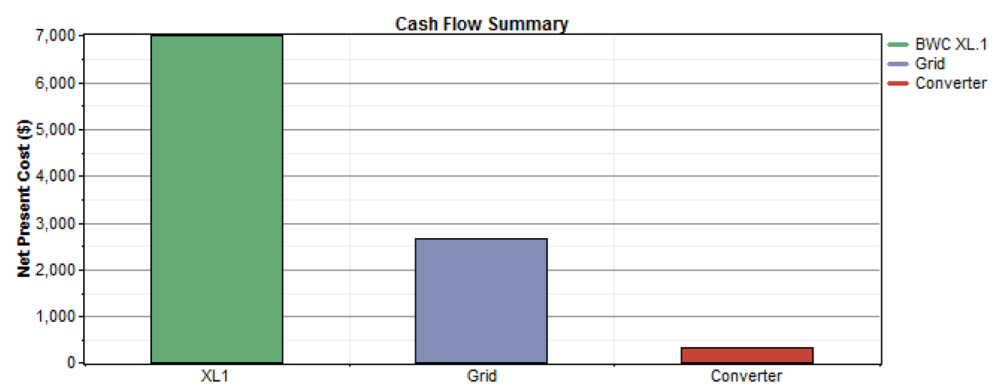

Figure 8: Cash flow summary of wind/grid system.

Table 1: Amount of pollutants produced by different configurations.

\begin{tabular}{lcccc}
\hline Pollutant emission & PV/G & Grid only & PV/W/G & W/G \\
\hline Carbon dioxide, $\mathrm{CO}_{2}$ & 268 & 1952 & -156 & 1526 \\
Carbon monoxide, $\mathrm{CO}$ & 0 & 0 & 0 & 0 \\
Unburned hydrocarbons, UHC & 0 & 0 & 0 & 0 \\
Particulate matter, $\mathrm{PM}$ & 0 & 0 & 0 & 0 \\
Sulfur dioxide, $\mathrm{SO}_{2}$ & 1.16 & 8.46 & -0.678 & 6.62 \\
Nitrogen oxides, $\mathrm{NO}_{\mathrm{X}}$ & 0.568 & 4.14 & -0.332 & 3.24 \\
\hline
\end{tabular}




\subsection{Payback period}

Since the capital cost of developing renewable energy sources is very expensive, it is very likely that loan bank is required. It is important to know how long it will take to recover from the investment cost. However, the payback period calculated in HOMER does not include the interest rate charged by bank. In this study, the FiT rate set at $\$ 0.3429 / \mathrm{kWh}$ is equal for all configurations. The payback period for PV/grid and PV/wind/grid systems is 9.46 and 13.5 years, respectively. However, the payback for wind/grid system cannot be calculated because the life-cycle cost of the system is higher than the grid-only system. Since the FiT is given for 21 years after commencement date, PV/grid and PV/wind/grid systems are very promising systems to be used here in Terengganu.

However, the FiT rate for wind system is still not provided by SEDA [6]. Thus, in this study, the FiT rate for PV/wind/grid system is varied from $\$ 0.3429$ to $\$ 0.5481 / \mathrm{kWh}$ to propose the suitable FiT for the system to compete with PV/grid system at a fix rate of $\$ 0.3429$ / $\mathrm{kWh}$ as shown in Fig. 9. From the figure, the FiT that produce 9.47-year payback period is $\$ 0.5166 / \mathrm{kWh}$, which is $50 \%$ higher than the FiT rate for PV/grid system.

Note that there are a few groups of people depending on the standard of living, which are poor, middle income and rich. The load profile considered in this article is suitable for poor people with the average electricity used is approximately $255 \mathrm{kWh} /$ month. The higher the standard of living, the bigger the house and more electrical appliance will be. Therefore, the average electricity used varies depend on the standard of living. In this study, four different load demands are considered which are double, triple and four times of $255 \mathrm{kWh} / \mathrm{month}$. Note that the higher the capacity of electricity purchased from TNB [12], the higher the price rate. However, the FiT rate for the PV panel above $4 \mathrm{~kW}$ up to $12 \mathrm{~kW}$ is reduced to $\$ 0.3359$ / $\mathrm{kWh}$. The payback period and COE for PV/grid system and price rate for grid-only system for four different load demands are plotted in Fig. 10.

From Fig. 10, the payback period is reduced for higher load demand. It is due to the higher capacity of PV panels installed depending on the peak load demand. The higher the capacity of PV panels, the more electricity can be generated and sold to the grid. Therefore, the payback is reduced.

In contrast, as the load demand increases, the $\mathrm{COE}$ and the price rate are also increased. The price rate in this figure is referred to price rate provided by TNB [12] for grid-only system. The COE in the figure is obtained for PV/grid system. Similar to load demand

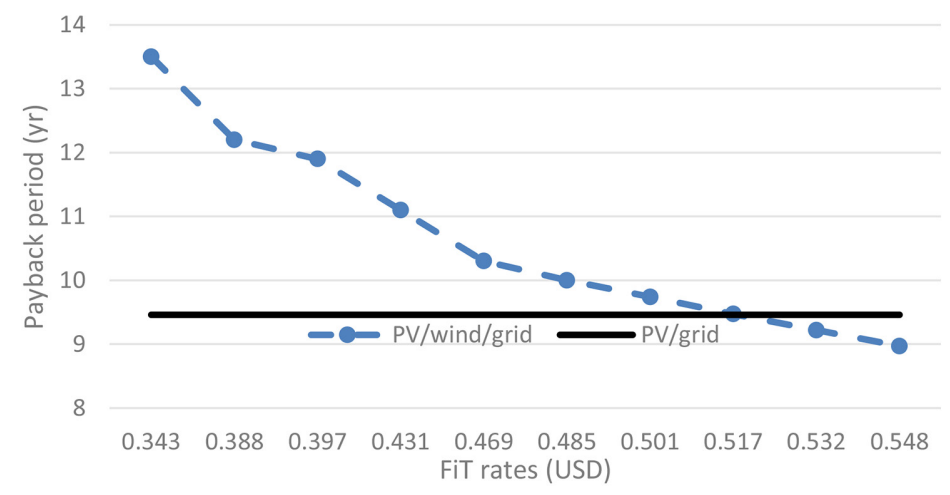

Figure 9: Payback period versus FiT rates for PV/wind/grid system. 


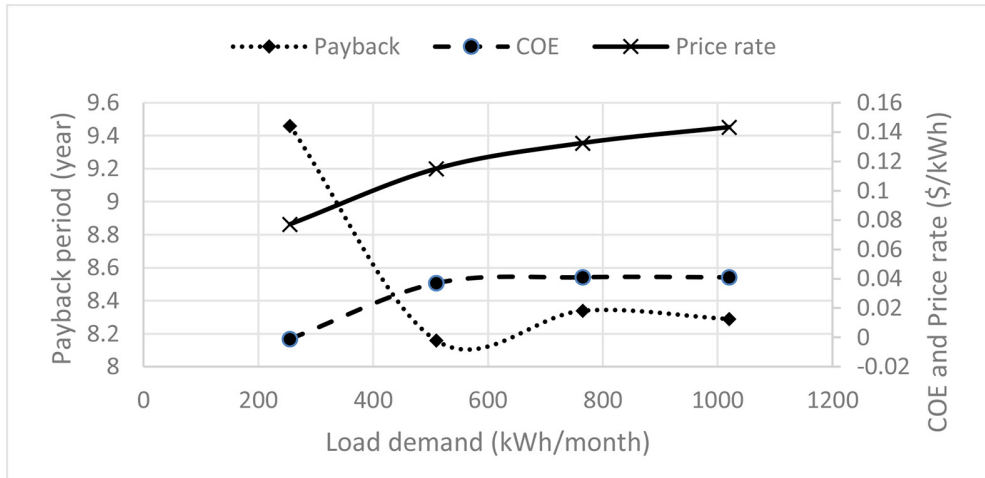

Figure 10: Payback, COE and price rate versus load demand.

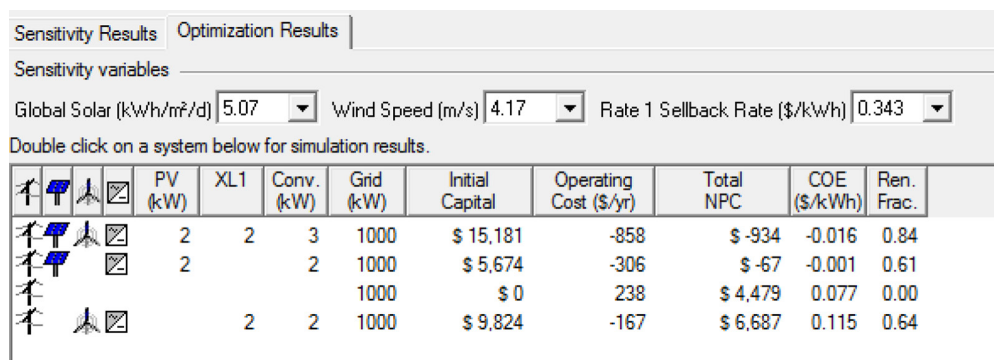

Figure 11: Optimization results at wind speed $4.17 \mathrm{~m} / \mathrm{s}$.

$255 \mathrm{kWh} /$ month as discussed above, the COE for all load demand is lower than the price rate offered by TNB. Although high load demand needs more than $4 \mathrm{~kW}$ PV panels with sellback rates reduced to $\$ 0.3359 / \mathrm{kWh}$, this rate is still higher than the price rate, thus very useful to generate income among consumers and lower down the COE.

\subsection{Sensitivity analysis}

In the sensitivity analysis, the parameter of wind speed is [3.17:1.0:7.17] $\mathrm{m} / \mathrm{s}$ and the solar radiation is $[5: 0.5: 6.5] \mathrm{kWh} / \mathrm{m}^{2} / \mathrm{d}$. These parameters are varied to represent different locations in Terengganu. There are people living near the beach that has very strong wind and there are people living in the city with slow wind. The sellback rate is varied at the ratio of $\$[0.3429: 0.0174: 0.5169] / \mathrm{kWh}$ to see the effect of it on the optimal system configuration.

Result in Fig. 11 shows that at the average solar radiation and the lowest FiT rate, the PV/ wind/grid system can be the most optimal system at the location with wind speed $1 \mathrm{~m} / \mathrm{s}$ higher than the average value.

From the sensitivity analysis, we found that all the three parameters affect in choosing the most optimal configuration. As the FiT rate increases, the lower wind speed is needed to make the PV/wind/grid configuration the most optimal system. For the FiT rate $\$ 0.5169$ / $\mathrm{kWh}, \mathrm{PV} /$ wind/grid configuration is the best system when the wind speed is $3.43 \mathrm{~m} / \mathrm{s}$. However, this value is still higher than the average wind speed collected in this study. It is also noted that the wind/grid system can be implemented, which is better than grid-only system, 
when the FiT rate is increased up to $\$ 0.4299 / \mathrm{kWh}$, at wind speed $4.17 \mathrm{~m} / \mathrm{s}$, the average solar radiation with payback time is 12.2 years.

\section{CONCLUSIONS}

From this study, there are only two configurations that are promising to be used in Terengganu that are $\mathrm{PV} /$ grid and PV/wind/grid systems. These two configurations have COE lower than grid-only system. With the average wind speed and solar radiation, at the FiT rate given by SEDA, the most optimal system is a hybrid PV/grid. This system can generate income for consumer by selling the excess electricity to the grid and at the same time reduce the overall cost of electricity. The payback period for this system is 9.46 years. Furthermore, the payback period is fewer for higher load demand. The proposed system also generates electricity in a cleaner environment. The finding in this article hopefully may convince consumer and local bank to invest a high capital cost of the technology, promote FiT scheme provided by government and increase the public awareness in generating electricity from renewable energy sources.

\section{REFERENCES}

[1] Ardakani, F.J. \& Ardehali, M.M., Long-term electrical energy consumption forecasting for developing and developed economies based on different optimized models and historical data types. Energy, 65, pp. 452-461, 2014. http://dx.doi.org/10.1016/j.energy.2013.12.031

[2] U. S. Energy Information Administration (EIA). Retrieved from www.eia.gov, 15 June 2015.

[3] Benjamin, K.S., A qualitative factor analysis of renewable energy and Sustainable Energy for All (SE4ALL) in the Asia-Pacific. Energy Policy, 59, pp. 393-403, 2013. http://dx.doi.org/10.1016/j.enpol.2013.03.051

[4] The Economic Planning Unit, Tenth Malaysia Plan 2011-2015, Prime Minister's Department, Putrajaya, pp. 1-451, 2010.

[5] Abdullah, A.S., Abdullah, M.P, Hassan, M.Y. \& Hussin, F., Renewable energy costbenefit analysis under Malaysian Feed-In-Tariff, IEEE Student Conference on Research and Development (SCOReD), Malaysia, pp. 160-165, 2012.

http://dx.doi.org/10.1109/scored.2012.6518631

[6] Sustainable Energy Development Authority Malaysia (SEDA). Retrieved from www. seda.gov.my, 15 June 2015.

[7] Rosnazri, A., Ismail, D. \& Soib, T., A review on existing and future energy sources for electrical power generation in Malaysia. Renewable and Sustainable Energy Reviews, 16(6), pp. 4047-4055, 2012.

http://dx.doi.org/10.1016/j.rser.2012.03.003

[8] Rozlan, M.B.M., Zobaa, A.F. \& Abdel Aleem, S.H.E., The optimisation of stand-alone hybrid renewable energy systems using HOMER. International Review of Electrical Engineering, 6(4B), pp. 1802-1810, 2011.

[9] Muda, W.M.W. \& Fong, C.A., Simulation-based method to evaluate PV/wind hybrid renewable energy system in Terengganu. WIT Transactions on Ecology and the Environment, 186, pp. 91-102, 2014, ISSN 1743-3541.

[10] HOMER. Retrieved from http://www.homerenergy.com/, 22 July 2014.

[11] Gilbert, M.M., Renewable and Efficient Electric Power Systems, John Wiley \& Sons: Hoboken, NJ, pp. 240-256, 2004.

[12] Tenaga Nasional Berhad (TNB). Retrieved from www.tnb.com.my, 15 June 2015.

[13] NASA. Retrieved from https://eosweb.larc.nasa.gov/, 22 July 2014. 